\title{
REVIEW
}

\section{CD36, a scavenger receptor implicated in atherosclerosis}

\begin{abstract}
Young Mi Park ${ }^{1,2}$
CD36 is a membrane glycoprotein that is present on various types of cells, including monocytes, macrophages, microvascular endothelial cells, adipocytes and platelets. Macrophage CD36 participates in atherosclerotic arterial lesion formation through its interaction with oxidized low-density lipoprotein (oxLDL), which triggers signaling cascades for inflammatory responses. CD36 functions in oxLDL uptake and foam cell formation, which is the initial critical stage of atherosclerosis. In addition, oxLDL via CD36 inhibits macrophage migration, which may be a macrophage-trapping mechanism in atherosclerotic lesions. The role of CD36 was examined in in vitro studies and in vivo experiments, which investigated various functions of CD36 in atherosclerosis and revealed that CD36 deficiency reduces atherosclerotic lesion formation. Platelet CD36 also promotes atherosclerotic inflammatory processes and is involved in thrombus formation after atherosclerotic plaque rupture. Because CD36 is an essential component of atherosclerosis, defining the function of CD36 and its corresponding signaling pathway may lead to a new treatment strategy for atherosclerosis.
\end{abstract}

Experimental \& Molecular Medicine (2014) 46, e99; doi:10.1038/emm.2014.38; published online 6 June 2014

Keywords: atherosclerosis; CD36; cell signaling; macrophage; oxidized LDL; scavenger receptor

\section{INTRODUCTION}

CD36 is a pattern recognition receptor that is expressed on various types of cells. CD36 binds multiple ligands and mediates different biological processes. Recent studies have demonstrated that CD36 is involved in the progression of atherosclerosis and that genetic deletion of CD36 or blockage of the CD36-induced signaling cascade reduces atherosclerotic lesion formation. CD36 has significant roles in different stages of the atherogenic process and consequently can be regarded as an important molecule in the progression of atherosclerosis. This paper provides an overview of reported functions of CD36, updates on the elucidation of CD36-mediated cell signaling, and its implications in atherosclerosis.

\section{CD36 STRUCTURE AND LIGANDS}

CD36, an $88-\mathrm{kDa}$ transmembrane glycoprotein receptor, is expressed on various cell types, including monocytes and macrophages; platelets; microvascular endothelial cells; adipocytes; epithelial cells in the kidney and cardiac myocytes. ${ }^{1}$ CD36 belongs to the class B scavenger receptor family, which also includes scavenger receptor $\mathrm{B} 1$ and lysosomal integral membrane protein $2 .^{2} \mathrm{CD} 36$ is encoded by the human $C d 36$ gene, which is located on chromosome 7 (7q11.2) and consists of 15 exons. The CD36 protein is composed of a single peptide chain of 472 amino acids and is organized into two transmembrane domains: two very short cytoplasmic domains and a large glycosylated extracellular domain (Figure 1). The extensive glycosylation of CD36 is required for intracellular trafficking onto the cell membrane. ${ }^{3}$

CD36 binds many different ligands including thrombospondin-1, oxidized phospholipids (oxPL), oxidized low-density lipoprotein (oxLDL), hexarelin, fibrillar $\mathrm{A} \beta$ amyloid peptides and long-chain fatty acids. CD36 also binds Plasmodium falciparum-infected erythrocytes, bacterial cell wall components of Staphylococcus and Mycobacterium, cell-derived microparticles and apoptotic cells. The binding site for each ligand is different; thrombospondin-1 binds to the CLESH-1 domain (CD36 LIMP II Emp Structural Homology-1) that resides in amino acids 93-155. The binding site for oxPL is located in amino acids 157-171, and the binding site for oxLDL is nearby in the $155-183$ sequence. ${ }^{4}$ Thrombospondin1 binding to endothelial CD36 inhibits angiogenesis by inducing apoptosis. ${ }^{5}$ As a fatty acid translocase, CD36 binds long-chain free fatty acids and facilitates their

\footnotetext{
${ }^{1}$ Department of Molecular Medicine, Ewha Womans University School of Medicine, Seoul, Republic of Korea and ${ }^{2}$ Ewha Global Top 5 Research Program, Ewha Womans University, Seoul, Republic of Korea

Correspondence: Dr YM Park, Ewha Womans University School of Medicine, 911-1, Mok-dong, Yangcheon-gu, Seoul 158-710, Republic of Korea.

E-mail: parkym@ewha.ac.kr

Received 5 June 2013; revised 17 March 2014; accepted 8 April 2014
} 


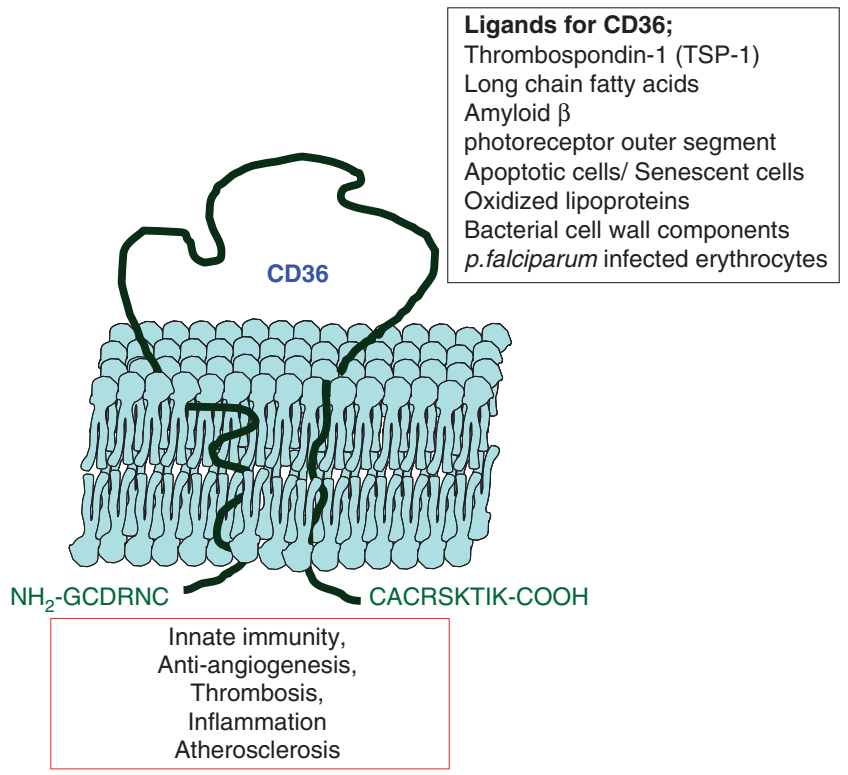

Figure 1 CD36 binds various ligands and functions in many biological processes. CD36 is a transmembrane receptor composed of two transmembrane domains, two very short cytoplasmic domains and a large glycosylated extracellular domain. CD36 is expressed in a variety of cell types, such as monocytes/ macrophages, microvascular endothelial cells, adipocytes and microglia and platelets, and binds various ligands. CD36 is implicated in many biological processes including innate immunity, anti-angiogenesis, thrombosis, inflammation and atherosclerosis.

transport into cells. This function of CD36 provides an energy source for beta-oxidation to myocytes and lipid storage to adipocytes. ${ }^{6}$

oxPL are known to play an important role in atherosclerosis and are known to be ligands for CD36. Phospholipids are essential components of lipoproteins and cell membranes, and are composed of fatty acids bound to a glycerol backbone with a polar head group. Phospholipids, particularly those containing unsaturated fatty acids, are susceptible to free-radical or enzymatic oxidation by reactive oxygen and nitrogen species generated by myeloperoxidase, lipoxygenase and other enzymes present in the vessel wall. ${ }^{7}$ Modification of phospholipids produces conformational changes, including oxidized fatty acids protrusion from the hydrophobic membrane or lipoprotein interior into the more polar aqueous compartment. Thus, modified phospholipids gain access and are able to interact with the pattern recognition receptor CD36. ${ }^{8}$ oxPL are accumulated under conditions of oxidative stress, such as infection and inflammation, and are also generated by necrotic and apoptotic cells. ${ }^{9}$ Extensive studies have revealed the chemical and structural characteristics of oxidized, modified lipids on the surface of cell membranes and/or lipoprotein particles that serve as ligands for CD36. Early studies revealed that the lipid portions of oxidized lipoproteins and apoptotic cells retain a significant portion of CD36-binding activity and that oxidized phosphatidylcholine is the primary ligand. ${ }^{10-12}$

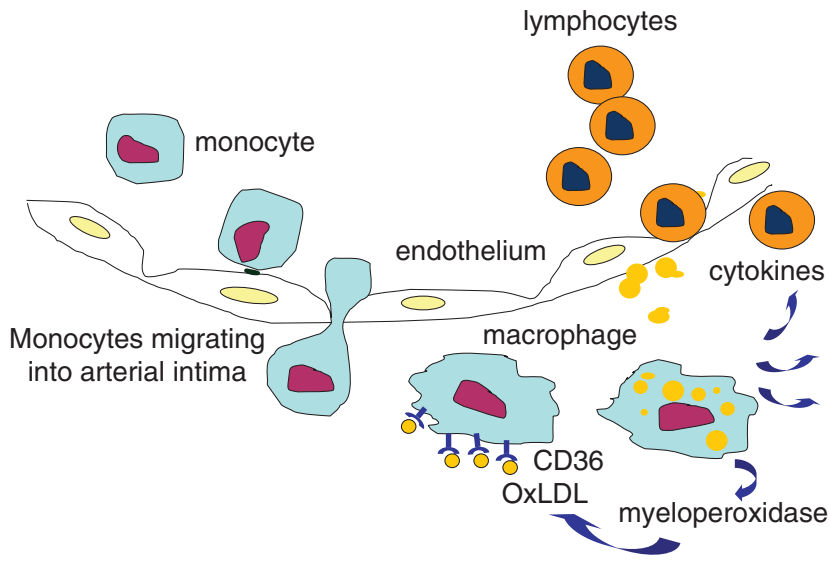

Figure 2 Macrophage trapping as a mechanism of atherosclerosis. The atherosclerotic process is initiated by monocyte entry into the arterial intima, followed by differentiation of these cells into macrophages. Macrophages internalize oxidized LDL (oxLDL) through scavenger receptors such as CD36 and are trapped in the arterial intima. They promote further inflammatory responses by secreting cytokines, which recruit other immune cells to the lesion. Progression of the atherosclerotic inflammation induces arterial lumen narrowing.

Podrez et al. ${ }^{10}$ reported that the structural characteristics for binding $\mathrm{CD} 36$ require phospholipids with an sn-2 acyl group that incorporates a terminal $\gamma$-hydroxy (or oxo)$\alpha, \beta$-unsaturated carbonyl (oxidized phosphatidylcholine ${ }_{\mathrm{CD} 36}$ ). In addition, oxPL with reactive groups covalently bind to proteins and form lipid-protein adducts. Both the free oxPL and the adducted forms are recognized by CD36. ${ }^{13}$

\section{MACROPHAGE CD36 MEDIATES FOAM CELL FORMATION AND PROMOTES ATHEROSCLEROSIS}

Foam cell formation is the initial critical step of atherosclerosis. The atherogenic process starts with the transmigration of blood-circulating monocytes into the arterial intima, where they differentiate into macrophages. ${ }^{14}$ Macrophages bind and internalize oxLDL through CD36. ${ }^{15}$ The internalized oxLDL provides its specific oxidized lipids as ligands for the nuclear hormone receptor PPAR- $\gamma$ and upregulates the expression of CD36, which is called an 'eat me signal.' This facilitates further uptake of oxLDL. ${ }^{16,17}$ Activated macrophages secrete oxidants, including myeloperoxidase, which oxidizes LDL and thus, enlarges the pool of oxLDL. ${ }^{18}$ The interaction between CD36 and oxLDL also induces the secretion of cytokines that recruit immune cell infiltrates in the arterial intima, ${ }^{19}$ and the arterial inflammation provoked by foam cells induces arterial narrowing, establishing atherosclerotic vascular diseases (Figure 2).

Macrophages harvested from $C d 36$-null mice are defective in oxLDL uptake, and Cd36-null mice with atherosclerosisprone background, including ApoE null or LDL receptor-null genotypes, showed less atherosclerotic lesion formation than ApoE null or $L D L$ receptor-null mice on a high-fat diet. ${ }^{20-22}$ A bone marrow transplantation study also revealed that the 
atherogenic mechanism is dependent on macrophage CD36. Mice that received Cd36-null macrophages had profoundly less atherosclerotic lesion formation, and reintroduction of macrophages with CD36 induced a twofold increase in the atherosclerotic lesion area. ${ }^{23}$ In addition, treatment with a competitive peptide ligand (EP80317), derived from the growth hormone-releasing peptide family that blocks the oxLDL-binding site of CD36, also reduced atherosclerotic lesions by $51 \%$ in ApoE-null mice. ${ }^{24}$ However, another study with a different $C d 36$-null mouse strain showed that ApoE/Cd36 double-null mice that were fed a high-fat diet had a modest reduction or even an increase in some atherosclerotic lesions compared with ApoE-null mice. Moore et al. ${ }^{25}$ also reported that a reduced lipid accumulation in peritoneal macrophages was coupled to significantly higher plasma cholesterol levels in male but not female ApoE/Cd36 double-null mice in comparison with ApoE-null mice. These contradictory observations were originally highly controversial. As suggested by Witztum and Collot-Teixeira et al., ${ }^{26,27}$ the differences may have been attributable to the use of two different mouse strains. The apparent controversy about the role of CD36 in murine atherosclerosis has been tempered by recent studies from Guy et al., ${ }^{21}$ which showed significant atheroprotection in an additional Cd36-null strain crossed with the ApoE-null strain and in a different atherosclerosis model, the $L D L$ receptor-deficient strain. ${ }^{21}$ Furthermore, two recent papers from Moore et al. ${ }^{25}$ reported significant atheroprotection (approaching levels observed in Guy et al. ${ }^{21}$ reports) in the Cd36/ApoE-null strain developed in their lab. ${ }^{30}$

The addressed studies, therefore, confirm that macrophage $\mathrm{CD} 36$ promotes atherosclerosis through the interaction with oxLDL.

\section{CD36: A SIGNALING MOLECULE THAT COMPRISES MULTIMOLECULAR COMPLEXES}

Many studies have revealed that CD36 transduces signals, although it lacks known intracellular signaling domains, such as kinase, phosphatase, g-protein binding or scaffolding domains. CD36 is known to physically associate with src family non-receptor tyrosine kinases, such as fyn, lyn and yes. ${ }^{31-33}$ In macrophages, the interaction between CD36 and oxLDL induces the phosphorylation of lyn and the subsequent activation of the mitogen-activated kinases Jun-kinase (JNK) 1 and 2. JNK activation mediates the uptake of oxLDL; the treatment of oxLDL-loaded macrophages with a JNK inhibitor was associated with a reduced oxLDL uptake. Atherosclerotic arterial lesions from mice had significantly increased levels of activated JNK compared with arterial tissue from nonatherosclerotic mice. ${ }^{34}$ Recently, a guanine nucleotide exchange factor, Vav, was revealed to be in the CD36mediated signaling cascade. Vav is activated by src family kinases and mediates the activation of the small-molecular weight $G$ proteins Rac and Rho. In addition, Vav is a scaffold protein for various signaling molecules including phospholipase $\mathrm{C}$ and dynamin. A recent paper showed that oxLDL induces Vav activation in macrophages, and Vav-null macrophages have reduced oxLDL uptake. Inhibition of dynamin, a Vav-interacting protein that functions in endocytic vesicle fission, blocked the uptake of oxLDL (Figure 3). ${ }^{35}$ Consequently, ApoE/vav1 double-null mice showed reduced atherosclerotic lesion formation compared with ApoE-null mice. ${ }^{36}$

IRGM1, another member of the small GTPase family that is highly expressed on macrophages, also mediates the internalization of CD36 and oxLDL. Macrophages from IRGM1null mice exhibited impaired CD36 internalization and oxLDL uptake, and IRGM1-null mice had reduced atherosclerotic

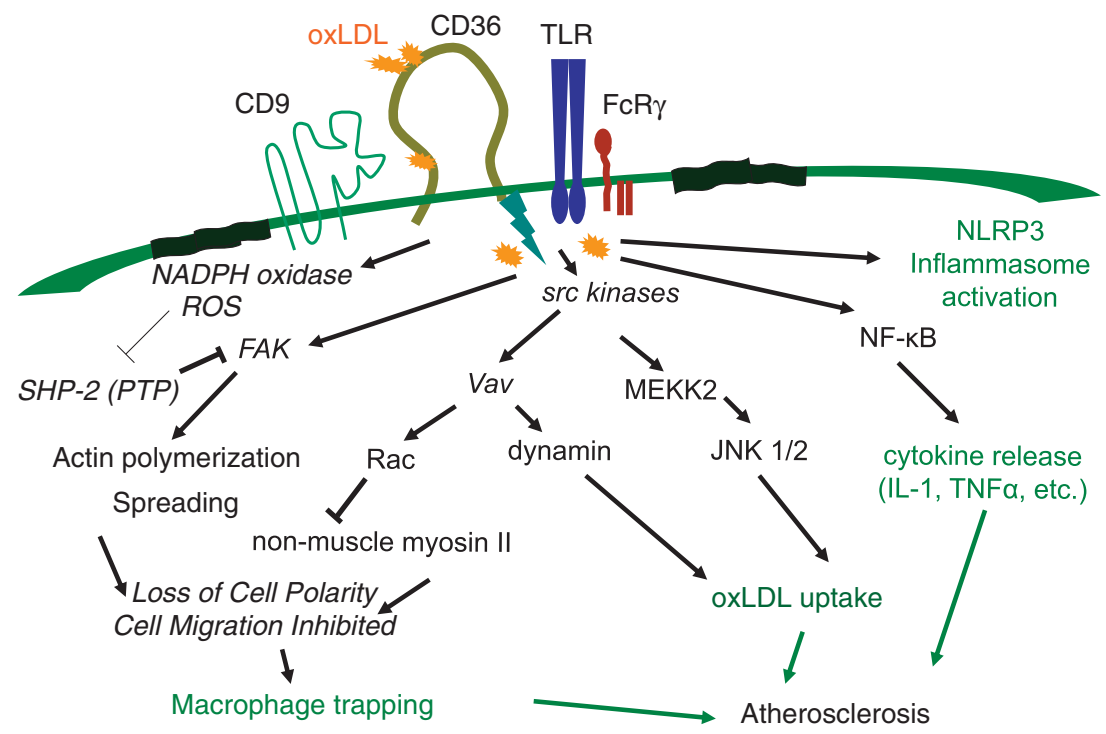

Figure 3 CD36-mediated signaling promotes atherosclerosis. The interaction between CD36 and oxidized LDL (oxLDL) provokes signaling cascades that mediate the uptake of oxLDL, cytokine production and macrophage trapping, thus promoting the atherosclerotic inflammatory process. 
lesion formation. ${ }^{37}$ OxLDL via CD36 induces the activation of other mitogen-activated kinases such as p38 mitogen-activated kinase and ERK 1/2. ${ }^{38}$ Signaling mediated by CD36 activates nuclear factor kappa beta. CD36-deficient macrophages have reduced nuclear factor kappa beta activation and reduced the release of interleukin (IL) $-1 \beta$ and tumor necrosis factor- $\alpha .{ }^{39}$

CD36 has diverse downstream signaling pathways and functions by interacting with other membrane receptors such as integrins, toll-like receptors (TLRs) and tetraspanins, including CD9. ${ }^{40,41}$ Macrophage CD36 responds to lipoteichoic acid on the membrane of Staphylococcus aureus and diacylated lipoproteins, depending on interactions with TLR2/6. ${ }^{42,43}$ The CD36-mediated uptake of oxLDL, the CD36mediated phagocytosis of $P$. falciparum malaria-parasitized erythrocytes and the endocytosis of CD36 are all independent of TLR2, while the activation of TLR2 enhances CD36mediated uptake. ${ }^{34,44}$ A recent study revealed that CD36 induces the assembly of the TLR4/6 heterodimer, which is responsible for the responses to oxLDL and amyloid- $\beta$, including inflammatory gene expression, IL-1 $\beta$ release and nuclear factor kappa beta activation. ${ }^{30}$ Sheedy et al. ${ }^{45}$ showed that CD36, via the binding and uptake of endogenous soluble ligands, including oxLDL, amyloid- $\beta$ peptide and amylin peptide, delivers two signals to promote the assembly of the cytoplasmic protein complex NLRP3 inflammasome, during sterile inflammation (as in atherosclerosis and Alzheimer's disease). The signals for NLRP3 inflammasome activation include 'signal 1,' which upregulates expression of IL-1 family members and some Nod-like receptors, and 'signal 2,' which leads to inflammasome assembly and secretion of IL-1 family members. ${ }^{46}$ CD36 directs soluble cargo, including oxLDL and soluble amyloid- $\beta$, to the lysosomal compartment where it is crystalized. The crystals destabilize the lysosomal membranes and induce inflammasome activation. $^{45}$ In accordance, CD36-deficient ApoE-null mice have less cholesterol crystal accumulation in atherosclerotic plaque and lower serum concentrations of IL-1 compared with ApoE-null mice. ${ }^{45}$ These studies reveal a mechanism by which CD36 promotes sterile inflammation.

The interaction between platelet-activating factor receptor and CD36 also mediates oxLDL uptake and IL-10 production. $^{47}$ Rios et al. ${ }^{47}$ showed that oxLDL promotes colocalization of platelet-activating factor receptor and CD36 in lipid rafts, and this colocalization is required for oxLDL uptake and oxLDL-induced IL-10 production.

A recent paper verified a mechanism by which the CD36containing multimolecular signaling complex enables internalization of CD36 and its ligands. Heit et al. ${ }^{48}$ demonstrated that CD36 resides in heterogeneous membrane receptor complexes that contain integrin $\beta 1 / \beta 2$ and the tetraspanins CD9 and CD81, and that this receptor complex links CD36 to the immunoreceptor tyrosine activation motif-bearing adaptor FcR $\gamma$ (FcER1G). Coupling to an immunoreceptor tyrosine activation motif adaptor allows CD36 to engage Src and Syk kinases and triggers internalization of CD36 and its bound ligands.
Therefore, macrophage CD36 coordinates with many other signaling partners and functions as a signaling molecule that promotes atherosclerosis by mediating foam cell formation and the release of inflammatory mediators.

\section{CD36-MEDIATED CYTOSKELETAL MODULATION INDUCES MACROPHAGE TRAPPING IN ATHEROSCLEROTIC PLAQUE}

Characteristically, atherosclerotic inflammation does not spontaneously resolve, which leads to irreversible arterial remodeling. Macrophage activation is a typical attribute of atherogenic inflammation. In contrast with acute inflammation, in which inflammatory responses are resolved by the emigration of infiltrated immune cells to draining lymph nodes, during atherogenic inflammation, macrophages are trapped in atherosclerotic lesions and continue propagating the inflammatory response without resolution. However, previous studies revealed that, under certain conditions, atherosclerotic lesions regress concurrently with macrophage emigration. ${ }^{49-51}$ Llodra et $a .^{51}$ induced regression of atherosclerotic plaque by transplanting arterial segments with atherosclerotic plaque from hypercholesterolemic mice into normal mice. This macrophage-trapping mechanism suggests novel approaches to the re-mobilization of lipid-laden macrophages from atherosclerotic lesions to facilitate disease regression and treatment. My work in Silverstein's laboratory reproduced findings reported nearly 26 years ago by Quinn et al. ${ }^{52}$ that oxLDL inhibits macrophage migration. We attempted to define the mechanism and show that CD36 mediates oxLDL-induced inhibition of macrophage migration. In vitro and in vivo migration assays indicated that oxLDL inhibited wild-type macrophage migration but not Cd36-null macrophages. OxLDL facilitates cell spreading by activating focal adhesion kinase through src-kinases. However, the inactivation of src homology 2-containing phosphotyrosine phosphatase (SHP-2) leads to sustained focal adhesion kinase activation, which results in the dysregulation of cytoskeletal assembly and disassembly and the loss of macrophage mobility. Inactivation of SHP-2 occurs through reactive oxygen species-mediated oxidative modification of the enzyme. Therefore, the blockage of the CD36-mediated signaling cascade by antioxidants and nicotinamide adenine dinucleotide phosphate oxidase inhibitors blocks the effect of oxLDL and restores macrophage migration in the presence of oxLDL. $^{53}$ Loss of macrophage cell polarity is another mechanism of oxLDL macrophage trapping. Our recent study revealed that oxLDL, through CD36, induces front-end lamellipodia retraction and the loss of cell polarity. The mechanism is caused by the oxLDL-induced activation of the Vav/Rac pathway and the subsequent inactivation of nonmuscle myosin II. Thus, Vav deletion or Rac inhibition blocks the effect of oxLDL on macrophage cell polarity and migration (Figure 3). ${ }^{54}$ These studies identified and suggested molecules in CD36-mediated signaling as new targets for reversing atherosclerosis. 
CD36 ACTIVATES PLATELETS, WHICH EXERT PROATHEROGENIC ACTIONS

Platelets promote thrombus formation after atherosclerotic plaque rupture, and are also involved in the initiation and development of the inflammatory process of atherosclerosis. ${ }^{55}$

Podrez et al. ${ }^{56}$ showed that oxLDL binding to CD36 activates platelets, inducing the expression of P-selectin and the activation of integrin $\alpha_{\mathrm{II}} \beta_{3}$. Recent studies from Silverstein's lab revealed that oxLDL binding to CD36 provokes platelet signaling and drives the platelets to become hyperactive. ${ }^{57,58}$ Platelets cultured with oxLDL were more sensitive to a low dose of ADP, the classic platelet activator. This process was mediated by the CD36-induced activation of JNK and Vav. ${ }^{57,58}$ A phosphoproteomic analysis of platelets revealed additional signaling pathways that mediate oxidized phospholipid/CD36-induced platelet activation, including Src family kinases, Syk, and phospholipase $\mathrm{C}-\gamma^{59}$ These data support the previous observation by Eitzman et al. ${ }^{60}$ that high-fat diet-fed ApoE-null mice had faster thrombi formation at the site of vascular injury. Accordingly, Cd36-null mice with an $A p o E$-null background showed slower thrombotic response than $A p o E$-null mice when challenged with vascular injury. ${ }^{57}$ Similarly, oxPL on the endothelial cell-derived microparticles also bind to platelet CD36 and promote thrombosis in mice with ferric chloride $\left(\mathrm{FeCl}_{3}\right)$-induced vascular injury. ${ }^{61}$ Advanced glycation end product, which is abundant in the blood of diabetic patients, also functions as a CD36 ligand and augments the response of platelets to ADP, promoting faster thrombosis in an animal model. ${ }^{62}$

Recent studies suggested that oxLDL, bound by platelets via scavenger receptors, exerts additional pro-atherogenic effects. Platelets interact with oxLDL and release atherosclerosispromoting chemokines. ${ }^{63}$ Furthermore, platelets internalize oxLDL, and these lipid-laden platelets activate the endothelium and inhibit endothelial regeneration. ${ }^{64}$ Platelets also mediate the conversion of monocytes into foam cells. Curtiss et al. ${ }^{65}$ showed that platelets facilitate cholesteryl ester accumulation in peripheral blood mononuclear cell-derived macrophages. A recent study by Badrnya et al. ${ }^{66}$ reinforces this observation by elucidating the role of CD36 in this process. In their study, they found that platelets form aggregates with monocytes in response to oxLDL, and this aggregate facilitates oxLDL uptake by monocytes in a CD36-dependent manner. Platelets activated by oxLDL promote monocyte extravasation in the thioglycollate-elicited peritonitis model. In addition, an in vitro experiment using transwell-migration assays also showed that oxLDL/CD36 platelet interactions enhanced monocyte migration across a human umbilical vein endothelial cell monolayer. ${ }^{66}$

\section{GENETIC VARIATIONS OF CD36}

The role of CD36 has been extensively studied since the generation of mice with $\mathrm{CD} 36$ genetic deletion. The genetic deletion of CD36 led to a reduction in the generation of atherosclerotic plaque in mice. In humans, several $C d 36$ gene mutations have been reported to result in a diminished expression of CD36 protein. ${ }^{67-70}$ The two mutation types are categorized into type I and type II CD36 deficiencies. Type I deficiency is characterized by the lack of expression of CD36 in many cell types, including monocytes, macrophages and platelets. In type II deficiency, CD36 is deficient only in platelets. ${ }^{68-75}$ However, the physiological consequences of the CD36 deficiency have not been clearly verified. Patients with type II CD36 deficiency have normal platelet functions, ${ }^{76}$ while the incidence of cardiomyopathy, hyperlipidemia and insulin resistance are relatively high in these patients. ${ }^{.7-80}$ It is not clear if the effects of human CD36 deficiency are caused by the lack of CD36 in certain cell types or if there are aberrant functions of mutant CD36 or any compensatory effects. Therefore, additional studies are warranted to clarify the effects of CD36 deficiency in humans.

\section{SOLUBLE CD36: A MARKER FOR METABOLIC SYNDROME INCLUDING ATHEROSCLEROSIS}

Non-cell bound CD36 has been isolated from human plasma and is referred to as soluble CD36 (sCD36). The level of sCD36 represents the expression level of CD36 in various cell types and tissues in human and rodent models of insulin resistance and type 2 diabetes. The concentration of $\mathrm{sCD} 36$ is approximately fivefold higher in plasma of obese diabetic subjects than in lean healthy subjects. ${ }^{81}$ In concordance with the role of CD36 in atherogenic inflammation, the sCD36 level was correlated with cardiovascular mortality in a cohort of chronic renal disease patients $^{82}$ and with intima-media thickness measured by ultrasound. ${ }^{83}$ HMG-CoA reductase inhibitor (statin) treatment reduced the serum concentration of $\mathrm{sCD} 36 .{ }^{82}$ However, whether sCD36 is composed of full-length CD36 or a proteolytic fragment of the CD36 extracellular domain has not been determined. Therefore, additional studies that investigate the structure of $\mathrm{sCD} 36$, the mechanism of sCD36 release, and the role of sCD36 are needed.

\section{CONCLUSION}

As a signaling molecule, CD36 plays significant roles in atherogenic processes, including foam cell formation, release of inflammatory mediators, macrophage trapping and thrombosis. Therefore, verification of the CD36-mediated signaling pathway may suggest novel therapeutic targets and a new strategy for the treatment of atherosclerosis. Recent studies of multimolecular complex formation, induced by CD36, revealed details about $\mathrm{CD} 36$ signal regulation and the manner in which CD36 drives various functions. Because CD36 binds a variety of ligands and functions in many different biological processes, a ligand-specific signaling pathway for CD36 should be examined. The atherogenic function of CD36 has been demonstrated in animal studies and in vitro experiments. However, only a few studies have examined CD36 in humans. Moreover, previous reports about type II CD36 deficiency in humans contradicted observations from animal studies. Therefore, additional studies that focus on the function of CD36 in humans are warranted to target this molecule for the treatment of atherosclerosis. 


\section{ACKNOWLEDGEMENTS}

This work was supported by the National Research Foundation of Korea (NRF) Grant funded by the Korean Government (MSIP) (No. NRF-2012R1A1A1013250).

1 Febbraio M, Hajjar DP, Silverstein RL. CD36: a class B scavenger receptor involved in angiogenesis, atherosclerosis, inflammation and lipid metabolism. J Clin Inv 2001; 108: 785-791.

2 Calvo D, Dopazo J, Vega MA. The CD36, CLA-1 (CD36L1), and LIMPII (CD36L2) gene family: cellular distribution, chromosomal location, and genetic evolution. Genomics 1995; 25: 100-106.

3 Hoosdally SJ, Andress EJ, Wooding C, Marin CA, Linton KJ. The human scavenger receptor CD36; glycosylation status and its role in trafficking and function. J Biol Chem 2009; 284: 16277-16288.

4 Navazo P, Daviet L, Ninio E, McGregor JL. Identification on human CD36 of a domain (155-183) implicated in binding oxidized low-density lipoproteins (Ox-LDL). Arterioscler Thromb Vasc Biol 1996; 16: 1033-1039.

5 Dawson DW, Pearce SFA, Zhong R, Silverstein RL, Frazier WA, Bouck NP. CD36 mediates the inhibitory effects of thrombospondin-1 on endothelial cells. J Cell Biol 1997; 138: 707-717.

6 Abumrad NA, el-Maghrabi MA, Amri EZ, Lopez E, Grimaldi PA. Cloning of a rat adipocyte membrane protein implicated in binding or transport of long-chain fatty acids that is induced during peadipocyte differentiation. Homology with human CD36. J Biol Chem 1993; 268: 17665-17668.

7 Hansson GK. Immune mechanism in atherosclerosis. Arterioscler Thromb Vasc Biol 2001; 20: 1876-1890.

8 Greenberg ME, Li XM, Gugiu BG, Gu X, Qin J, Salomon RG et al. The lipid whisker model of the structure of oxidized cell membranes. J Biol Chem 2008; 283: 2385-2396.

9 Leitinger $N$. Oxidized phospholipids as modulators of inflammation in atherosclerosis. Curr Opin Lipidol 2003; 14: 421-430.

10 Podrez EA, Febbraio M, Sheibani N, Schmitt D, Silverstein RL, Hajjar DP et al. The macrophage scavenger receptor CD36 is the major receptor for LDL modified by monocyte-generated reactive nitrogen species. J Clin Invest 2000; 105: 1095-1108.

11 Boullier A, Gillotte KL, Hörkkö S, Green SR, Friedman P, Dennis EA et al. The binding of oxidized low density lipoprotein to mouse CD36 is mediated in part by oxidized phospholipids that are associated with both the lipid and protein moieties of the lipoprotein. J Biol Chem 2000; 275: 9163-9169.

12 Bird DA, Gillotte KL, Hörkkö S, Friedman P, Dennis EA, Witztum JL et al. Receptors for oxidized low-density lipoprotein on elicited mouse peritoneal macrophages can recognize both the modified lipid moieties and the modified protein moieties: Implications with respect to macrophage recognition of apoptotic cells. Proc Natl Acad Sci USA 1999; 96: 6347-6352.

13 Podrez EA, Poliakov E, Shen Z, Zhang R, Deng $Y$, Sun M et al. A novel family of atherogenic oxidized phospholipids promotes macrophage foam cell formation via the scavenger receptor CD36 and is enriched in atherosclerotic lesions. J Biol Chem 2002; 277: 38517-38523.

14 Libby P. Inflammation in atherosclerosis. Nature 2002; 407: 233-241.

15 Endeman G, Stanton LW, Madden KS, Bryant CM, White RT, Protter AA. CD36 is a receptor for oxidized low density lipoprotein. J Biol Chem 1993; 268: $11811-11816$.

16 Nagy L, Tontonoz P, Alvarez JG, Chen H, Evans RM. Oxidized LDL regulates macrophage gene expression through ligand activation of PPAR- $\gamma$. Cell 1998; 93: 229-240.

17 Tontonoz P, Nagy L, Alvarez JG, Thomazy VA, Evans RM. PPAR- $\gamma$ promotes monocyte/macrophage differentiation and uptake of oxidized LDL. Cell 1998; 93: 241-252.

18 Carr AC, McCall MR, Frei B. Oxidation of LDL by myeloperoxidase and reactive oxygen species; reaction pathways and antioxidant protection. Arterioscler Thromb Vasc Biol 2000; 20: 1716-1723.

19 Jiang Y, Wang M, Huang K, Zhang Z, Shao N, Zhang Y et al. Oxidized lowdensity lipoprotein induces secretion of interleukin- $1 \beta$ by macrophages via reactive oxygen species-dependent NLRP3 inflammasome activation. Biochem Biophys Res Commun 2012; 425: 121-126.
20 Febbraio M, Podrez EA, Smith JD, Hajjar DP, Hazen SL, Hoff HF et al. Targeted disruption of the class B scavenger receptor CD36 protects against atherosclerotic lesion development in mice. J Clin Invest 2000; 105: 1049-1056.

21 Guy E, Kuchibhotla S, Silverstein R, Febbraio M. Continued inhibition of atherosclerotic lesion development in long term western diet fed CD360/ apoE0 mice. Atherosclerosis 2007; 192: 123-130.

22 Kuchibhotla S, Vanegas D, Kennedy DJ, Guy E, Nimako G, Morton RE et al. Absence of CD36 protects against atherosclerosis in ApoE knockout mice with no additional protection provided by absence of scavenger receptor A I/II. Cardiovasc Res 2008; 78: 185-196.

23 Febbraio M, Guy E, Silverstein RL. Stem cell transplantation reveals that absence of macrophage CD36 is protective against atherosclerosis. Arterioscler Thromb Vasc Biol 2004; 24: 2333-2338.

24 Marleau S, Harb D, Bujold K, Avallone R, Iken K, Wang Y. EP 80317, a ligand of the CD36 scavenger receptor, protects apolipoprotein E-deficient mice from developing atherosclerotic lesions. FASEB J 2005; 19: $1869-1871$

25 Moore KJ, Kunjathoor VV, Koehn SL, Manning JJ, Tseng AA, Silver JM et al. Loss of receptor-mediated lipid uptake via scavenger receptor $A$ or CD36 pathways does not ameliorate atherosclerosis in hyperlipidemic mice. J Clin Invest 2005; 115: 2192-2201.

26 Witztum JL. You are right, too. J Clin Invest 2005; 115: 2072-2075.

27 Collot-Teixeira S, Martin J, McDeromott-Roe C, Poston R, McGregor JL. CD36 and macrophages in atherosclerosis. Cardiovasc Res 2007; 75: 468-477.

28 Kennedy DJ, Kuchibhotla SD, Guy E, Park YM, Nimako G, Vanegas D et al. Dietary cholesterol plays a role in CD36-mediated atherogenesis in LDLRknockout mice. Arterioscler Thromb Vasc Biol 2009; 29: 1481-1487.

29 Manning-Tobin JJ, Moore KJ, Seimon TA, Bell SA, Sharuk M, Alvarez-Leite Jl et al. Freeman M.W. Loss of SR-A and CD36 activity reduces atherosclerotic lesion complexity without abrogating foam cell formation in hyperlipidemic mice. Arterioscler Thromb Vasc Biol 2009; 29: 19-26.

30 Stewart CR, Stuart LM, Wilkinson K, van Gils JM, Deng J, Halle A et al. CD36 ligands promote sterile inflammation through assembly of a Toll-like receptor 4 and 6 heterodimer. Nat Immunol 2010; 11: 155-161.

31 Chen K, Febbraio M, Li W, Silverstein RL. A specific CD36-dependent signaling pathway is required for platelet activation by oxLDL. Circ Res 2008; 102: 1512-1519.

32 Moore KJ, El Khoury J, Medeiros LA, Terada K, Geula C, Luster AD et al. A CD36-initiated signaling cascade mediates inflammatory effects of betaamyloid. J Biol Chem 2002; 277: 47373-47379.

33 Dawson DW, Pearce SF, Zhong R, Silverstein RL, Frazier WA, Bouck NP. CD36 mediates the in vitro inhibitory effects of thrombospondin-1 on endothelial cells. J Cell Biol 1997; 138: 707-717.

34 Rahaman SO, Lennon DJ, Febbraio M, Podrez EA, Hazen SL, Silverstein RL. A CD36-dependent signaling cascade is necessary for macrophage foam cell formation. Cell Metab 2006; 4: 211-221.

35 Rahaman SO, Zhou G, Silverstein RL. Vav protein guanine nucleotide exchange factor regulates CD36 protein-mediated macrophage foam cell formation via calcium and dynamin-dependent processes. J Biol Chem 2011; 286: 36011-36019.

36 Rahaman SO, Li W, Silverstein RL. Vav guanine nucleotide exchange factors regulate atherosclerotic lesion development in mice. Arterioscler Thromb Vasc Biol 2013; 33: 2053-2057.

37 Xia F, Li R, Wang C, Yang S, Tian L, Dong H et al. IRGM 1 regulates oxidized LDL uptake by macrophage via actin-dependent receptor internalization during atherosclerosis. Sci Rep 2013; 3: 1867.

38 Zhao M, Liu Y, Wang X, New L, Han J, Brunk UT. Activation of the p38 MAP kinase pathway is required for foam cell formation from macrophages exposed to oxidized LDL. APMIS 2002; 110: 458-468.

39 Yamashita S, Hirano K, Kuwasako T, Janabi M, Toyama Y, Ishigami M et al. Physiological and pathological roles of a multi-ligand receptor CD36 in atherogenesis: insights from CD36-deficient patients. Mol Cell Biochem 2007; 299: 19-22.

40 Miao WM, Vasile E, Lane WS, Lawler J. CD36 associates with CD9 and integrins on human blood platelets. Blood 2001; 97: 1689-1696.

41 Akira S. Toll-like receptor signaling. J Biol Chem 2003; 278: 38105-38108.

42 Hashimoto M, Tawaratsumida K, Kariya H, Kiyohara A, Suda Y, Krikae F et al. Not lipoteichoic acid but lipoproteins appear to be the dominant immunobiologically active compounds in Staphylococcus aureus. J Immunol 2006; 177: 3162-3169. 
43 Triantafilou M, Gamper G, Haston RM, Mouratis MA, Morath S, Hartung T et al. Membrane sorting of toll-like receptor (TLR)-2/6 and TLR 2/1 heterodimers at the cell surface determines heterotypic associations with CD36 and intracellular targeting. J Biol Chem 2006; 281: 31002-31011.

44 Erdman LK, Cosio G, Helmers AJ, Gowda DC, Grinstein S, Kain KC. CD36 and TLR interactions in inflammation and phagocytosis: implications for malaria. J Immuol 2009; 183: 2452-2459.

45 Sheedy FJ, Grebe A, Rayner KJ, Kalantari P, Ramkhelawon B, Carpenter SB et al. CD36 coordinates NLRP3 inflammasome activation by facilitating intracellular nucleation of soluble ligands into particulate ligands in sterile inflammation. Nat Immunol 2013; 14: 812-820.

46 Rathinam VA, Vanaja SK, Fitzgerald KA. Regulation of inflammasome signaling. Nat Immunol 2012; 13: 333-342.

47 Rios FJ, Ferracini M, Pecenin M, Koga MM, Wang Y, Ketelhuth DF et al. Uptake of oxLDL and IL-10 production by macrophages requires PAFR and CD36 recruitment into the same lipid rafts. PLOS ONE 2013; 8: e76893.

48 Heit B, Kim H, Cosío G, Castaño D, Collins R, Lowell CA. Multimolecular signaling complexes enable Syk-mediated signaling of CD36 internalization. Dev Cell 2013; 24: 372-383.

49 Reis ED, Lie J, Fayad ZA, Rong JX, Hansoty D, Aguinaldo JG et al. Dramatic remodeling of advanced atherosclerotic plaques of the apolipoprotein E-deficient mouse in a novel transplantation model. Vasc Surgery 2001; 34: 541-547.

50 Chereshnev I, Trogan E, Omerhodzic S, Itskovich V, Aguinaldo JG, Fayad ZA et al. Mouse model of heterotopic aortic arch transplantation. J Surg Res 2003; 111: 171-176.

51 Llodra J, Angeli V, Liu J, Trogan E, Fisher EA, Randolph GJ. Emigration of monocyte-derived cells from atherosclerotic lesions characterizes regressive, but not progressive, plaques. Proc Natl Acad Sci USA 2004; 101: 11779-11784.

52 Quinn MT, Parthasarathy S, Fong LG, Steinberg D. Oxidatively modified low density lipoproteins: a potential role in recruitment and retention of monocyte/macrophagesduring atherogenesis. Proc Natl Acad Sci USA 1987; 84: 2995-2998.

53 Park YM, Febbraio M, Silverstein RL. CD36 modulates migration of mouse and human macrophages in response to oxidized LDL and may contribute to macrophage trapping in the arterial intima. J Clin Invest 2009; 119: 136-145.

54 Park YM, Drazba JA, Vasanji A, Egelhoff T, Febbraio M, Silverstein RL. Oxidized LDL/CD36 interaction induces loss of cell polarity and inhibits macrophage locomotion. Mol Cell Biol 2012; 23: 3057-3068.

55 Fuentes QE, Fuentes QF, Andrés V, Pello OM, de Mora JF, Palomo GI. Role of platelets as mediators that link inflammation and thrombosis in atherosclerosis. Platelets 2013; 24: 255-262.

56 Podrez EA, Byzova TV, Febbraio M, Salomon RG, Ma Y, Valiyaveettil M et al. Platelet CD36 links hyperlipidemia, oxidant stress and a pro-thrombotic phenotype. Nat Med 2007; 13: 1086-1095.

57 Chen K, Febbraio M, Li W, Silverstein RL. A specific CD36-dependent signaling pathway is required for platelet activation by oxidized low-density lipoprotein. Circ Res 2008; 102: 1512-1519.

58 Chen K, Li W, Major J, Rahaman SO, Febbraio M, Silverstein RL. Vav guanine nucleotide exchange factors link hyperlipidemia and a prothrombotic state. Blood 2011; 117: 5744-5750.

59 Zimman A, Titz B, Komisopoulou E, Biswas S, Graeber TG, Podrez EA. Phosphoproteomic analysis of platelets activated by pro-thrombotic oxidized phospholipids and thrombin. PLOS ONE 2014; 9: e84488.

60 Eitzman DT, Westrick RJ, Xu Z, Tyson J, Ginsburg D. Hyperlipidemia promotes thrombosis after injury to atherosclerotic vessels in apolipoprotein E-deficient mice. Arterioscler Thromb Vasc Biol 2000; 20: 1831-1834.

61 Ghosh A, Li W, Febbraio M, Espinola RG, McCrae KR, Cockrell E et al. Platelet CD36 mediates interactions with endothelial cell-derived microparticles and contributes to thrombosis in mice. J Clin Invest 2008; 118: 1934-1943.

62 Zhu W, Li W, Silverstein RL. Advanced glycation end products induce a prothrombotic phenotype in mice via interaction with platelet CD36. Blood 2012; 119: 6136-6144.

63 Siegel-Axel D, Daub K, Seizer P, Lindemann S, Gawaz M. Platelet lipoprotein interplay: trigger of foam cell formation and driver of atherosclerosis. Cardiovasc Res 2008; 78: 8-17.

64 Daub K, Seizer P, Stellos K, Krämer BF, Bigalke B, Schaller M et al. Oxidized LDL-activated platelets induce vascular inflammation. Semin Thromb Hemost 2010; 36: 146-156.

65 Curtiss LK, Black AS, Takagi Y, Plow EF. New mechanism for foam cell generation in atherosclerotic lesions. J Clin Invest 1987; 80: 367-373.
66 Badrnya S, Schrottmaier WC, Kral JB, Yaiw KC, Volf I, Schabbauer G. Platelets mediate oxidized low-density lipoprotein-induced monolayer extravasation and foam cell formation. Arterioscler Thromb Vasc Biol 2013; 34: 571-580.

67 Lipsky RH, Ikeda H, Medved ES. A dinucleotide repeat in the thrid intron of CD36. Hum Mol Gent 1994; 3: 217.

68 Yamamoto N, Akamatsu N, Sakuraba H, Yamazaki H, Tanoue K. Platelet glycoprotein IV(CD36) deficiency is associated with the absence (type I) or the presence (type II) of glycoprotein IV on monocytes. Blood 1994; 83: 392-397.

69 Kashiwagi H, Tomiyama Y, Kosugi S, Shiraga M, Lipsky RH, Nagao N et al. Family studies of type II CD36 deficient subjects: linkage of a CD36 allele to a platelet-specific mRNA expression defect(s) causing type II CD36 deficiency. Thromb Haemost 1995; 72: 758-763.

70 Kashiwagi H, Tomiyama Y, Nozaki S, Kiyoi T, Tadokoro S, Matsumoto K et al. Analyses of genetic abnormalities in type I CD36 deficiency in Japan: idendification and cell biological characterization of two novel mutations that cause CD36 deficiency in man. Hum Genet 2001; 108: 459-466.

71 Hanawa H, Watanabe K, Nakamura T, Ogawa Y, Toba K, Fuse I et al. Identification of cryptic splice site, exon skipping, and novel point mutations in type I CD36 deficiency. J Med Genet 2002; 39: 286-291.

72 Imai M, Tanaka T, Kintaka T, Ikemoto T, Shimizu A, Kitaura Y. Genomic heterogeneity of type II CD36 deficiency. Clin Chim Acta 2002; 321: 97-106.

73 Kashiwagi H, Tomiyama Y, Kosugi S, Shiraga M, Lipsky RH, Kanayama Y et al. Identification of molecular defects in a subject with type I CD36 deficiency. Blood 1994; 83: 3545-3552.

74 Fukuchi K, Nozaki S, Yoshizumi T, Hasegawa S, Uehara T, Nakagawa Tet al. Enhanced myocardial glucose use in patients with a deficiency in long-chain fatty acid transport (CD36 deficiency). J Nucl Med 1999; 40: 239-243.

75 Hirano K, Kuwasako T, Nakagawa-Toyama Y, Janabi M, Yamashita S, Matsuzawa Y. Pathophysiology of human genetic CD36 deficiency. Trends Cardiovasc Med 2003; 13: 136-141.

76 Yamamoto N, Ikeda H, Tandon NN, Herman J, Tomiyama Y, Mitani T et al. A platelet membrane glycoprotein (GP) deficiency in healthy blood donors: Naka-platelets lack detectable GPIV(CD36). Blood 1990; 76: $1698-1703$

77 Watanabe K, Ohta Y, Toba K, Ogawa Y, Hanawa H, Hirokawa Y et al. Myocardial CD36 expression and fatty acid accumulation in patients with type I and II CD36 deficiency. Ann Nucl Med 1998; 12: 261-266.

78 Teraguchi M, Ikemoto Y, Unishi G, Ohkohchi H, Kobayashi Y. Influence of CD36 deficiency on heart disease in children. Circ J 2004; 68: 435-438.

79 Yanai $\mathrm{H}$, Chiba H, Morimoto M, Abe K, Fujiwara H, Fuda $\mathrm{H}$ et al. Human CD36 deficiency is associated with elevation in low-density lipoproteincholesterol. Am J Med Genet 2000; 93: 299-304.

80 Miyaoka K, Kuwasako T, Hirano K, Nozaki S, Yamashita S, Matsuzawa Y. CD36 deficiency associated with insulin resistance. Lancet 2001; 357: 686-687.

81 Handberg A, Levin K, Højlund K, Beck-Nielsen H. Identification of the oxidized low-density lipoprotein scavenger receptor CD36 in plasma: a novel marker of insulin resistance. Circulation 2006; 114: 1169-1176.

82 Chmielewski M, Bragfors-Helin AC, Stenvinkel P, Lindholm B, Anderstam B. Serum soluble CD36, assessed by a novel monoclonal antibody-based sandwich ELISA, predicts cardiovascular mortality in dialysis patients. Clin Chim Acta 2010; 411: 2079-2082.

83 Handberg A, Højlund K, Gastaldelli A, Flyvbjerg A, Dekker JM, Petrie J et al. Plasma SCD36 is associated with markers of atherosclerosis, insulin resistance and fatty liver in a nondiabetic healthy population. J Intern Med 2012; 271: 294-304.

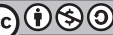

This work is licensed under a Creative Commons Attribution-NonCommercial-ShareAlike 3.0 Unported License. The images or other third party material in this article are included in the article's Creative Commons license, unless indicated otherwise in the credit line; if the material is not included under the Creative Commons license, users will need to obtain permission from the license holder to reproduce the material. To view a copy of this license, visit http://creativecommons.org/licenses/by-nc-sa/3.0/ 